\title{
Monitoring of water quality in a surface reservoir FEAGRI, UNICAMP
}

\author{
Mariana N. D. Silva*, Renata K. D. Zupiroli*, Vitor A. M. de Oliveira*, Juliana Martins, Maria L. Carra, Sheyla \\ Lisboa e Ariovaldo J. da Silva.
}

\begin{abstract}
In the same way as other water bodies, lakes that supply water to the artificial reservoir of School of Agricultural Engineering (FEAGRI) may be affected by physical, biological and/or chemical impacts at environmental conditions. Aiming to determine the characteristics of the reservoir used for irrigation in experimental field of FEAGRI, quantitative analyses were carried out monthly concerning physico-chemical properties of water. Results were compared to standards indicated by Resolution 357/2005 of National Environment Council (Conselho Nacional de Meio Ambiente, CONAMA) in order to classificate the waters from the artificial lake and assure the quality of irrigation water.
\end{abstract}

\section{Key words:}

Physico-chemical analyses, water quality, irrigation.

\section{Introduction}

The artificial reservoir of FEAGRI is destined for irrigation and this requires a specific monitoring to verify if it is suitable for use. Therefore, physical-chemical analyses of water were realized to characterize it throughout the year and classify it for irrigation use.

\section{Results and Discussion}

Analyses of $\mathrm{pH}$, turbidity, dissolved oxygen (DO), chemical oxygen demand (COD), phosphorus, nitrite, nitrate, and solids series of water streams entering and leaving the water reservoir of FEAGRI, which is supplied by a natural lake located at Unicamp. Analyses were carried out monthly during 11 months in the Laboratory of Sanitation and Environment of FEAGRI, according to the Standard Methods (APHA, 2012).

Results of analyses were compared to the standards of CONAMA Resolution 357/2005 for irrigation and grouped as the following classes: 1 for vegetables to be eaten in raw form and fruits with peel; 2 for vegetables, fruit plants, parks, gardens and sport fields; and 3 for arboreal cultures, cereals and fodder.

Parameters such as temperature, electrical conductivity, and COD are not listed in CONAMA Resolution 357/2005.

Image 1. Concentrations of nitrite $(\mathrm{mg} / \mathrm{L})$ at inlet and outlet compared to classes 1,2 and 3 of CONAMA Resolution 357/2005.

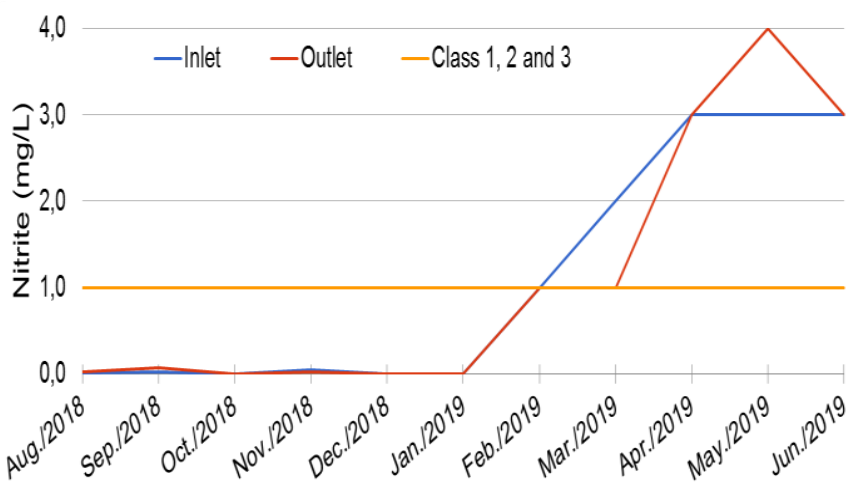

Image 2. Concentrations of phosphorus $(\mathrm{mg} / \mathrm{L})$ at inlet and outlet compared to classes 1,2 and 3 of CONAMA Resolution 357/2005.

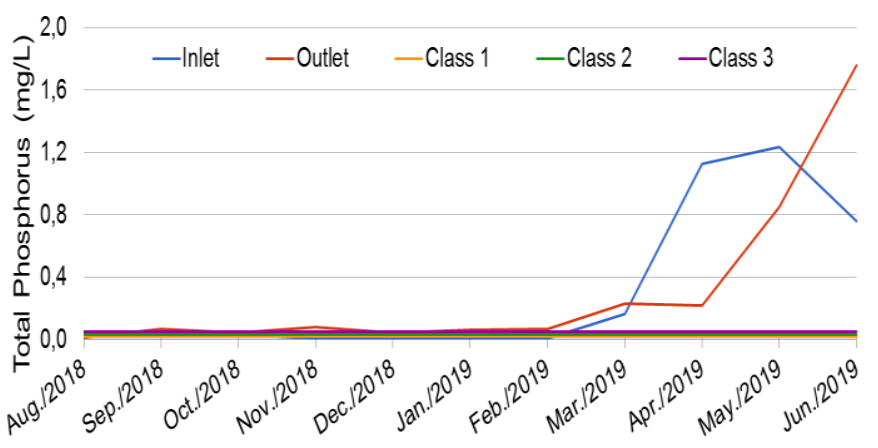

Image 1 shows that there were oscillations in concentration of nitrite from February to June both at inlet and outlet. Oscillations were also observed in Image 2, which reveals that there were expressive increases in phosphorus concentration starting in March. This can be due to the following possible factors: weather changes and variations in the water inlet stream.

Except for nitrite and phosphorus, other analyses do not present notable variations and belong to class 1 .

\section{Conclusions}

Analyses carried out in the study showed that, according to CONAMA Resolution 357/2005, the reservoir may be used for irrigation of vegetables to be eaten in raw form and fruits ingested with peel belonging to class 1.

\section{Acknowledgement}

We acknowledge the FEAGRI team, PIBIC$\mathrm{EM} / \mathrm{CNPq}$ and our monitors for the motivation of helping us by means of supply of resources for the analyses and aid for the development of this project.

\footnotetext{
APHA, $\boldsymbol{A W W A} \& \boldsymbol{W} \boldsymbol{W F}$. Standard methods for the examination of water and wastewater. 19 ed. Washington, DC: American Public Health Association, 2012.

Ministry of the Environment (MMA, Ministério do Meio Ambiente). Resolution No 357, 17th March of 2005, Published at DOU $n^{\circ} 053$, 03/18/2005, pages 58-63, 2005. Available at <http://www2.mma.gov.br/ port/conama/res/res05/res35705.pdf>. Visited in 22nd Jan. 2019.
} 